\title{
Dominant winter-time mesospheric wave signatures over a low latitude station, Hawaii $\left(20.8^{\circ} \mathbf{N}\right)$ : An investigation
}

\author{
A TAORI ${ }^{1, *}$ and M TAYLOR ${ }^{2}$ \\ ${ }^{1}$ National Atmospheric Research Laboratory, Gadanki, Pakala Mandal 517 112, Andhra Pradesh, India. \\ ${ }^{2}$ Center for Atmospheric and Space Sciences, Department of Physics, Utah State University, \\ Logan - Utah 84322, USA. \\ *e-mail: alok.taori@gmail.com
}

We utilize mesospheric $\mathrm{O}_{2}$ airglow emission intensity and temperature data collected during January-February 2003 on 17 consecutive nights from Maui, Hawaii $\left(20.8^{\circ} \mathrm{N}, 156.2^{\circ} \mathrm{W}\right)$ to study the dominant and long period wave features at mesospheric altitudes. Apart from large day-to-day variability, it is found that nocturnal data for the period under consideration was dominated by a terdiurnal tide-like wave. Together, a quasi 5-day wave is also noticed with significant amplitude.

\section{Introduction}

The mesospheric dynamics and its variability are governed by a variety of wave and tidal features (e.g., Forbes 1984; Fritts and Alexander 2003). Several investigations have revealed a high degree of variability in wave and tidal structures from time scales ranging from few hours to a solar cycle (Manson et al 2004; She et al 2004; Sridharan et al 2009). However, the database on the types, origin, characteristics and morphology of these waves is still very limited. Apart from various remote sensing radio and optical tools to investigate the wave and tidal processes occurring at mesospheric heights (e.g., Keckhut et al 1999; Pancheva et al 2004; Sridharan et al 2009), airglow monitoring is an important and cost effective means for the investigations of the upper atmospheric processes (Pant et al 2007; Gavrilyeva et al 2009). It is in general agreement now that dynamical processes including gravity waves, tides, planetary waves, etc., leave their signatures in the airglow emission intensities and their derived temperatures (Hines and Tarasick 1997). The present study carried out from a low latitude station Maui, Hawaii $\left(20.8^{\circ} \mathrm{N}\right.$, $156.2^{\circ} \mathrm{W}$ ) during January-February 2003 when quality data on 17 consecutive clear nights was available enabling one to estimate the amplitudes of a predominant tide-like nocturnal wave and planetary waves and their relative importance. We identify and characterize the dominant waves present in the data for the above duration.

\section{Instrumentation}

The Mesospheric Temperature Mapper (MTM) was developed in 1997 under the NSF Coupling Energetics and Dynamics of Atmospheric Regions (CEDAR) program to enhance upper atmospheric imaging capabilities. The MTM is a high performance, solid state imaging system capable of determining wave-induced fluctuations in the intensity and rotational temperatures of the $\mathrm{OH}(6,2)$ Meinel band and $\mathrm{O}_{2}(0,1)$ atmospheric band emissions. The MTM utilizes a large format $\left(6.45 \mathrm{~cm}^{2}\right)$, $1024 \times 1024$ pixel $\mathrm{CCD}$ array coupled to a $90^{\circ}$ circular field of view telecentric lens system. The high quantum efficiency $(\sim 50 \%$ at near infrared wavelengths) and low noise characteristics (dark current $\sim 0.1 \mathrm{e}^{-} / \mathrm{pixel} / \mathrm{sec}$ at $-50^{\circ} \mathrm{C}$ ) of the $\mathrm{CCD}$ array provide an exceptional capability for highquality nocturnal measurements of $\mathrm{OH}$ and $\mathrm{O}_{2}$ emission intensity $(<0.5 \%$ in $1 \mathrm{~min})$ and derived

Keywords. Airglow; wave; tides; mesosphere. 


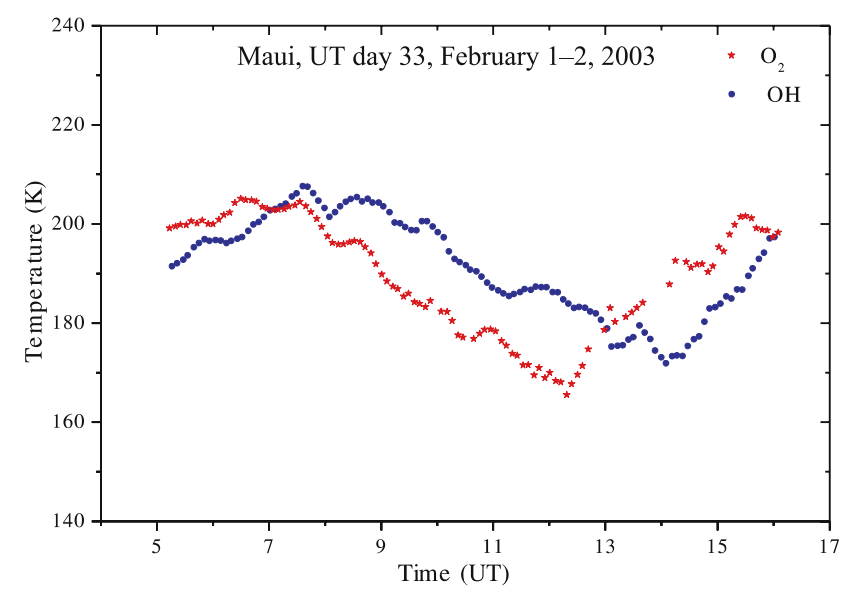

Figure 1. Typical temperature variability in mesospheric $\mathrm{OH}$ and $\mathrm{O}_{2}$ emissions. A large period wave together with smaller periodicity wave feature is evident in the data. Also, a clear downward phase progression of waves can be clearly noted.

rotational temperatures (precision $<1-2 \mathrm{~K}$ in $3 \mathrm{~min}$ ). The inherent linearity and stability of the MTM has also enabled seasonal investigations of the mesospheric temperature variability (Pendleton et al 2000; Taori and Taylor 2006; Taori et al 2007).

In operation, sequential exposures are made using a temperature stabilized filter wheel fitted with narrow band $(\Delta \lambda \sim 1.2 \mathrm{~nm})$ filters centered at 840.0 and $846.5 \mathrm{~nm}$ for the $\mathrm{OH}(6,2)$ Meinel band and 866.0 and $868.0 \mathrm{~nm}$ for the $\mathrm{O}_{2}$ $(0,1)$ atmospheric band measurements followed by a background sky measurement at $857.0 \mathrm{~nm}$. To enhance the precision of the temperature determinations the signal-to-noise ratio (SNR) of the data are increased by $8 \times 8$ binning on the chip to form a $128 \times 128$ super-pixel image with a resultant zenithal foot print of about $0.9 \times 0.9 \mathrm{~km}$ per super-pixel. Rotational temperatures are then computed separately for both emissions using the ratio method, as described eloquently by Meriweather (1984).

\section{Results and discussion}

Figure 1 is an example variability of the mesospheric $\mathrm{OH}$ and $\mathrm{O}_{2}$ temperature derived from the MTM data recorded on UT Day 33 in 2003 (February 1-2). The high quality data throughout the 11-hour observing interval show a welldefined long periodic oscillation. The peak-to-peak variation of $\sim 30 \mathrm{~K}$ is seen in the plot for both $\mathrm{OH}$ and $\mathrm{O}_{2}$ data. The short period waves with $\sim 0.5-1.0 \mathrm{~h}$ periodicity are also evident in the data. The well-defined long period wave structures exhibit the wave period of $\sim 10 \mathrm{~h}$ in both, $\mathrm{OH}$ and $\mathrm{O}_{2}$ temperature data. One can clearly note the upward propagation of this wave with $\mathrm{O}_{2}$ data leading the phase by $\sim 1.5 \mathrm{~h}$, indicative of a downward phase progression, a typical identification of upward propagating gravity waves. This phase difference results into an upward propagation velocity of $\sim 75 \mathrm{~m} / \mathrm{s}$ for assumed altitudes of $\sim 87$ and $\sim 94 \mathrm{~km}$ for $\mathrm{OH}$ and $\mathrm{O}_{2}$ emissions, respectively. Though, variability in airglow emissions are a resultant of emission height variability, chemistry and dynamics such as waves, the downward phase propagation confirms the wave nature of variability observed.

In this report, only $\mathrm{O}_{2}$ data were analyzed in a greater detail to identify the mesospheric variability and characterize the predominant waves existing at upper mesospheric altitude during UT Day 26-UT Day 42 in 2003 (because in general, OH intensity data exhibit a fast post-evening chemical decay which makes the estimation of longperiod wave periodicity and amplitudes difficult). It is important to note that long and uninterrupted optical datasets are difficult to get with the help of ground-based instruments. We average the $\mathrm{O}_{2}$ temperature and corresponding emission intensity data for $0.5 \mathrm{~h}$ bins to remove high frequency noise and to identify the variability that have significant amplitudes $(>2 \mathrm{~K})$. Figure 2 shows the raster scan contour plot for the temperature and intensity variability observed throughout the 17-day period for data visualization. The $\mathrm{x}$-axis in plot shows the UT days in the year 2003 while y-axis represents the UT time in hours. The $\mathrm{O}_{2}$ temperature data broadly ranges from 165 to $225 \mathrm{~K}$ while the corresponding emission intensity ranges from $1 \times 10^{4}$ to $1 \times 10^{5}$. The mesospheric $\mathrm{O}_{2}$ temperatures and intensity variability are dominated with waves having periodicities from $0.5 \mathrm{~h}$ to several hours. We can also notice that around 0600$0800 \mathrm{~h}$ UT, short period waves have large amplitudes while during 1000-1400 h UT long period waves with periodicity $\sim 8 \mathrm{~h}$ to few days have significant amplitudes $(>2 \mathrm{~K})$. Also an order of change in intensity data together with large temperature variations clearly indicates highly variable dynamical state of mesosphere owing to the large contribution from several wave and tidal processes.

To identify the predominant nocturnal wave in the data, we did averaging of nocturnal data to get a composite plot for the mean mocturnal temperature variation. Figure 3(a) exhibits the resultant nocturnal averaged data for the above-mentioned 17-day period from UT 26 to UT 42, 2003. Individual circles with error bars show the averaged data for every half hour period while the standard deviation in individual estimates are shown as error bars. A simple best-fit cosine model was utilized to get the estimates of the periodicity and 

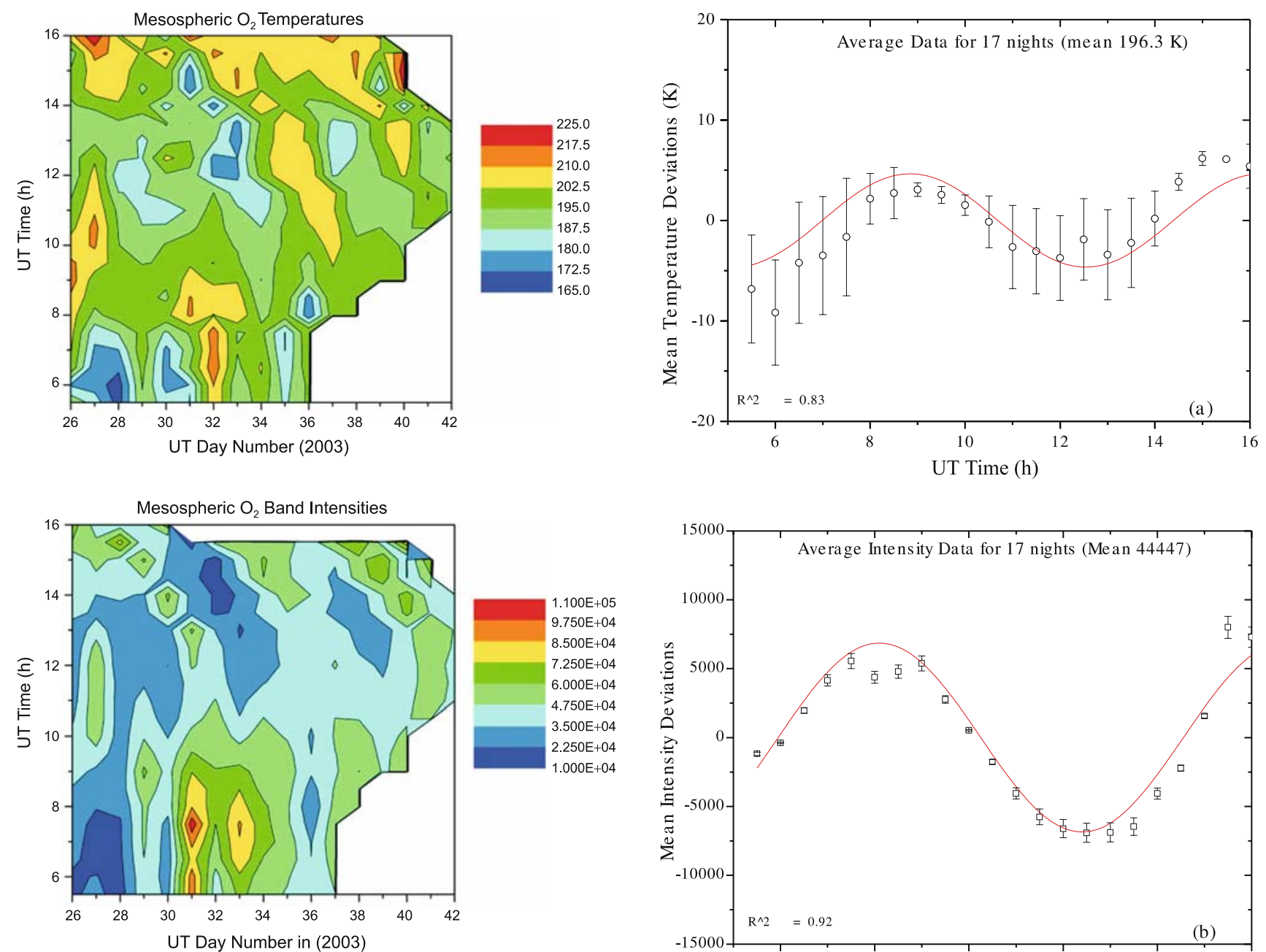

Figure 2. Raster scan plot for $0.5 \mathrm{~h}$ averaged data for 17 -day period from UT 26 to UT 42, 2003 for temperature (top panel) and intensity (bottom panel) variability. A dominant long period as well as short period waves are evident in both, temperature and intensity data.

phase of the prominent wave in the data which essentially should be the tide-like persistent wave in the temperature data. The best-fit results are shown in the plot as solid line curve. It is evident that a wave with $\sim 7.46 \mathrm{~h}$ periodicity and amplitude of $\sim 5 \mathrm{~K}$ exists in the data. Noteworthy is that our values agree well with earlier reported values of terdiurnal wave amplitude over Hawaii by Taori et al (2005), but for July 2002. Further, the bestfit model on the data for diurnal and semi-diurnal components revealed the amplitudes to be about $2 \mathrm{~K}$ and $1.5 \mathrm{~K}$ which are significantly smaller than GSWM-02 model estimates of $\sim 3.5 \mathrm{~K}$ and $\sim 4.5 \mathrm{~K}$, respectively for January-February months. Noteworthy here is that the terdiurnal tidal fit alone is able to explain the nocturnal variability indicating that during the observational period, terdiurnal tidal wave was the most dominant in the temperature data. This is in contrast to the observations made by Friedman et al (2009) who reported the

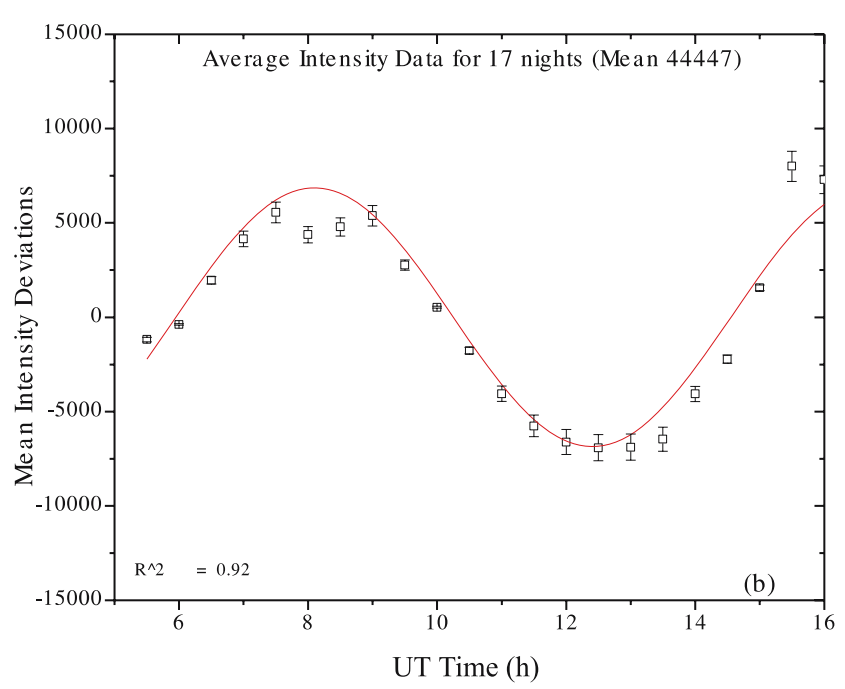

Figure 3. Composite data for nocturnal temperature variations for UT 26-UT 42 data for $\mathrm{O}_{2}$ temperature (top panel) and intensity (bottom panel) data. The best-fit clearly indicate the terdiurnal wave to be the most dominant in the data. Solid lines in each plot are simple best-fit cosine model results.

dominance of semi-diurnal tide with amplitudes as high as $10 \mathrm{~K}$ over Maui, Hawaii. Interesting to note is that they also report that SABER measured temperature values for semi-diurnal tides were $\sim 2-3 \mathrm{~K}$ which agrees well with our estimates for semi-diurnal tides. However, as our data is limited with only one cycle of terdiurnal temperature wave, still possibility of seeing a semi-diurnal structure cannot be fully eliminated. Further, as reported by Hocking and Hocking (2002) that wind and temperature tides have phase relation and hence, tidal features in wind and temperature need not peak at similar latitudes, we avoid discussing about semi- and ter-diurnal features observed in wind data which in recent times were discussed by Jiang et al (2009) for similar latitudes.

Further, to find if the similar wave structures exist in intensity data, we carry out similar 


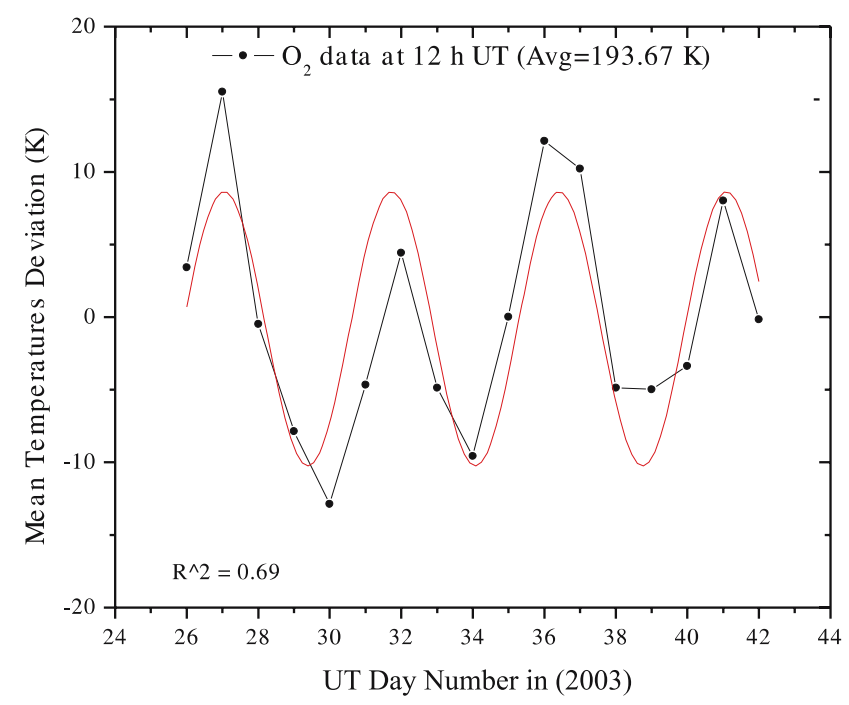

Figure 4. Variability in mesospheric $\mathrm{O}_{2}$ temperature data at $1200 \mathrm{~h}$ UT during the period under consideration. One can notice the presence of a quasi 5 -day wave in the data. The line connecting points are the data while the solid lines are best-fit on the data exhibiting the significant amplitudes of quasi 5-day wave.

averaging for the corresponding intensity data (shown in raster scan plot). Figure 3(b) shows the resultant average intensity plot for UT day 26 to UT day 42,2003 . Individual data points are shown as open boxes while the error bars exhibit the standard deviations in the data, i.e., the measure of the nocturnal variability. The best fit cosine model results are also shown in the plot as solid line curve which reveal the presence of a well defined $8.6 \mathrm{~h}$ wave. Understanding the complexity in mesospheric chemistry and dynamics, we assume that the intensity and temperature waves to be the signatures of a terdiurnal tide with periodicity of $\sim 8 \mathrm{~h}$. It is interesting to note that the intensity data show variations of $\sim 15-17 \%$ while the temperature data shown in figure 3(a) reveal only $\sim 3-4 \%$ variability around their mean values. As explained in literature (e.g., Taori and Taylor 2006; Guharay et al 2008) another wave-period dependent quantity that characterize the adiabatic perturbations associated with the propagating waves, 'Krassovsky parameter $\eta=|\eta|$ $\operatorname{Exp}(\mathrm{i} \Phi)$ ', can also be deduced for the predominant $\sim 8 \mathrm{~h}$ terdiurnal type wave. The ratio of percentage variations in intensity to the associated temperature by propagating wave gives the magnitude $\eta$, while the phase difference between the intensity and temperature wave is defined as phase $\Phi$. The $\eta$ values being the transfer function between the intensity perturbations to the temperature ones, while $\Phi$ represents the differences caused by the chemistry (which may also introduce an altitudinal differences in temperature and intensity layers for $\mathrm{O}_{2}$ emissions). The magnitude $\eta$ turns out to be $\sim 5$ while the phase $\Phi$ is $\sim-35^{\circ}$. These values differ somewhat from the values of $\sim 6.5$ and $-60^{\circ}$ reported by Taori and Taylor (2006) but are well within the values reported by Guharay et al (2008) which range from $\sim 3$ to 9 for amplitudes and phase values -20 to $-45^{\circ}$. This also indicates that energy transfer relation has a seasonal variability which has a wider implication over the heat budget brought in the mesosphere by different wave processes.

The above highlight regarding the dominance of terdiurnal tides at mesospheric altitudes is considered important in connection to their occurrence. It has been understood that low and equatorial mesosphere is dominated by semi-diurnal and diurnal tides. There are few observations from mid and high latitudes that suggest terdiurnal tides amplitudes to be as large as $8 \mathrm{~K}$ (Pendleton et al 2000 and references cited therein) which are supported by some modelling efforts as well (Smith and Ortland 2001). However, in recent times, Taori et al (2005) have shown the dominant terdiurnal waves during summer-time over low latitudes. The present study exhibiting the dominance of terdiurnal wave during winter-time over low latitudes is an intriguing aspect which demands some more work and significant statistics on mesospheric temperature fields over low and equatorial latitudes so that terdiurnal tides can be appropriately incorporated in atmospheric models.

Further, as noted in figures 2 and 3, a long period $(>24 \mathrm{~h})$ planetary wave to be present in the data, we did an attempt to identify the type of wave by taking a time slice at $1200 \mathrm{UT}$ for all the days under consideration (UT day 26-42). Figure 4 shows the resultant data. Plotted in the figure are the mean deviations for all days of data at $1200 \mathrm{~h}$ UT with mean temperatures being $\sim 193.6 \mathrm{~K}$ (this is done to avoid the contribution from terdiurnal tide which has minimum amplitudes during 1100-1200 UT). It is striking to note the existence of a long period wave with periodicity $\sim 5$ days. At least three full cycles of this planetary wave are evident in the data with significant amplitudes. The best-fit results revealed the average amplitudes to be $\sim 8.5 \mathrm{~K}$ in mesospheric $\mathrm{O}_{2}$ temperature data. This shows a much larger contribution of quasi 5-day wave in upper mesospheric heat budget compared to the terdiurnal tides (as the tidal amplitude estimates are $\sim 5 \mathrm{~K}$ ) during the above said 17 days of duration in February 2003. At the same time, intensity data also exhibited a similar wave with $\sim 20 \%$ peak-to-peak variations. This results into the magnitude of $\eta$ to be $\sim 2.5$. It is also important to note that though there had been a number of reports on the presence of quasi 5-day wave in mesospheric wind data over low latitudes (e.g., Pancheva et al 2004; Riggin 
et al 2006), and mesospheric temperature data over mid and high latitudes (e.g., Merkel 2003), groundbased mesospheric temperatures showing the presence of quasi 5-day wave over low latitudes are extremely rare and our result is unique for the said reasons.

It is interesting to note that magnitudes of Krassovsky ratio for quasi 5-day planetary wave are much smaller than the persistent 8-h terdiurnal type of wave. In general, model studies reveal the short period waves to have smaller magnitudes compared to the long period waves. In the present case, it appears that efficiency of quasi 5 -day planetary waves to transfer the energy from density perturbations to the temperatures is much larger than the tide-like $\sim 8 \mathrm{~h}$ waves. This is a very important aspect for middle atmospheric circulation and energy budget estimation. However, this can only be verified with more data with supportive modelling work.

\section{Summary}

With the help of USU-MTM data at $\mathrm{O}_{2}$ wavelengths for January-February 2003 from UT Day 26 to UT Day 42, we investigate the dominant wave variability existing at upper mesospheric altitudes during winter-time. Our results exhibit short period gravity waves as well as a well defined long period $\sim 8 \mathrm{~h}$ terdiuranal tidal wave. Together, a clear evidence showing significant amplitudes of quasi 5-day waves is also noticed. The noted long period terdirunal tidal wave exhibited amplitude of $\sim 4-5 \mathrm{~K}$ in temperature data while $\sim 15 \%$ variations are recorded in the intensity data revealing the Krassovsky parameter $\sim 5$. The longer period quasi 5 -day wave exhibited $\sim 8.5 \mathrm{~K}$ amplitudes which are significantly higher than the predominant tide-like wave amplitudes. Such signatures and interplay of tides and planetary waves are possible at mesospheric altitudes but observational data is limited and also their significance is not well quantified owing to lack of statistics. In short, myriad wave properties at mesospheric altitudes remain uncharacterized and challenging for their parameterization in global circulation atmospheric models.

\section{Acknowledgements}

A Taori thanks the Director, NARL, Gadanki and Department of Space, Govt. of India for their consistent support for airglow research. The financial support for the USU-MTM was provided by NSF grant ATM-0003218 and ATM-0134150.

\section{References}

Forbes J M 1984 Middle atmospheric tides; J. Atmos. Terr. Phys. 46 1049-1067.

Fritts D C and Alexander M J 2003 Gravity wave dynamics and effects in the middle atmosphere; Rev. Geophys. 41 1003, doi: 10.1029/2001RG000106.

Friedman, Jonathan S, Xioli Zang, Xinzao Chu and Jeffery Forbes 2009 Longitudinal variation of solar semidiurnal tide in mesosphere and lower thermosphere at low latitudes observed from ground and space; J. Geophys. Res. 114 D11114, doi: 10.1029/2009JD011763.

Gavrilyeva G A, Ammosov P P and Koltovskoi I I 2009 Semidiurnal thermal tide in the mesopause region over Yakutia; Geomagnetism and Aeronomy 49(1) 110-114.

Guharay A, Taori A and Taylor M 2008 Summer-time nocturnal wave characteristics in mesospheric $\mathrm{OH}$ and $\mathrm{O}_{2}$ airglow emissions; Earth Planets and Space 60 973-979.

Hines C O and Tarasick D W 1997 Layer truncation and the Eulerian/Lagrangian duality in the theory of airglow fluctuations induced by gravity waves; J. Atmos. Terr. Phys. 59 327-334.

Hocking W K and Hocking A 2002 Temperature tides determined with meteor radar; Ann. Geophys. 20 1447-1467.

Jiang G, Xue J and Franke S 2009 The 8-hr tide in the mesosphere and lower thermosphere over Maui $\left(20.75^{\circ} \mathrm{N}\right.$, 156.43ํㅏ); Ann. Geophys. 27 1989-1999.

Keckhut P, Schmidlin F J, Hauchecorne A and Chanin M L 1999 Stratospheric and mesospheric cooling trend estimates from US rocketsondes at low-latitude stations $\left(8^{\circ} \mathrm{S}-34^{\circ} \mathrm{N}\right)$, taking into account instrumental changes and natural variability; J. Atmos. Sol. Terr. Phys. 61 447-459.

Manson A H, Meek C, Hagan M, Zhang X and Luo Y 2004 Global distributions of diurnal and semidiurnal tides: Observations from HRDI/UARS of the MLT region and comparisons with GSWM-02 (migrating and nonmigrating components); Ann. Geophys. 22 1529-1548.

Meriweather J W 1984 Ground based measurements of mesospheric temperatures by optical means; In: International Council of Scientific Unions Middle Atmosphere Program Hand Book MAP (ed.) Vincent R, 13 1-18, NASA, Green Belt, Md.

Merkel A W, Thomas G E, Palo S E and Bailey S M 2003 Observations of the 5-day planetary wave in PMC measurements from the Student Nitric Oxide Explorer Satellite; Geophys. Res. Lett. 30(4) 1196.

Pancheva D, Mitchell N J and Younger P T 2004 Meteor radar observations of atmospheric waves in the equatorial mesosphere/lower thermosphere over Ascension Island; Ann. Geophys. 22 387-404.

Pant, Tarun Kumar, Diwakar Tiwari, Vineeth C, Smitha V Thampi, Sridharan S, Devasia C V, Sridharan R, Gurubaran S and Sekar R 2007 Investigation on the mesopause energetics and its possible implications on the equatorial MLTI processes through coordinated daytime airglow and radar measurements; Geophys. Res. Lett. 34 15, doi: 10.1029/2007GL030193.

Pendleton W R, Taylor M J and Gardner L C 2000 Terdiurnal oscillations in $\mathrm{OH}$ Meinel rotational temperatures for fall conditions at northern mid-latitude sites; Geophys. Res. Lett. 27(12) 1799-1802.

Riggin, Dennis M, Han-Li Liu, Ruth S Lieberman, Raymond G Roble, James M Russell III, Christopher J Mertens, Martin G Mlynczak, Dora Pancheva, Steven J Franke, Yasuhiro Murayama and Alan H Manson 2006 Observations of the 5-day wave in the mesosphere and lower thermosphere; J. Atmos. Sol. Terr. Phys. 68 323-339. 
She C Y, Li T, Yuan T, Kawahara T and Krueger D A 2004 Tidal perturbations and variability in the mesopause region over Fort Collins, $\mathrm{CO}\left(41^{\circ} \mathrm{N}\right.$, $\left.105^{\circ} \mathrm{W}\right)$; Geophys. Res. Lett. 31 L24111, doi: 10.1029/ 2004GL021165.

Smith A K and Ortland D A 2001 Modeling and analysis of the structure and generation of the terdiurnal tide; J. Atmos. Sci. 58 3116-3134.

Sridharan S, Vishnu Prasad P and Bhavani Kumar Y 2009 A report on long-term trends and variabilities in middle atmospheric temperature over Gadanki $\left(13.51^{\circ} \mathrm{N}, 79.21^{\circ} \mathrm{E}\right) ;$ J. Atmos. Sol. Terr. Phys., doi: 10.1016/j.jastp.2008.09.017.
Taori A, Taylor M J and Franke S 2005 Terdiurnal wave signatures in the upper mesospheric temperature and their association with the wind fields at low latitudes $\left(20^{\circ} \mathrm{N}\right)$; J. Geophys. Res. 110 D09S06, doi: 10.1029/2004JD004564

Taori A and Taylor M J 2006 Characteristics of wave induced oscillations in mesospheric $\mathrm{O}_{2}$ emission intensity and temperatures; Geophys. Res. Lett. 33 L01813, doi: 10.1029/2005GL024442.

Taori A, Guharay A and Taylor M J 2007 On the use of simultaneous measurements of $\mathrm{OH}$ and $\mathrm{O}_{2}$ emissions to investigate wave growth and dissipation; Ann. Geophys. 25 639-643. 